full account of this work will appear shortly in the Astrophysical Journal.

Any observers planning to use a Nicol prism in connection with a spectroscope in the manner described will find a gas or candle flame illuminated with a beam of sun-light, concentrated by means of a large mirror or lens, extremely useful in making preliminary experiments.

For work on the polarisation of the corona, I believe that the artificial corona, which will be described next week, will be found most useful for preparatory work. Not only is it polarised, and polarised in the same way as the real corona, but it resembles it in every respect, and can be easily made of the same brilliancy. It would be well to work with particles of different size, giving different percentages of polarisation, and the picturesque refinements for producing the polar streamers could, of course, bc omitted. A lamp with a ground glass globe might be used to advantage, giving a distribution of polarisation more nearly like that of the actual corona.

Data regarding the plane of polarisation in the streamers would be useful in formulating a theory of the streamers. These, it seems to me, can be conceived as formed in two ways : they may be streams of coronal particles moving in curved paths, in which case the plane of polarisation should be everywhere strictly radial, or, what is extremely improbable, they may be caused by divergent beams of light coming from the polar regions of the sun and moving in curved paths owing to the rapid decrease in the refractive index of the sun's atmosphere in an outward direction. If this were the case, the plane of polarisation would turn with the streamer. This latter hypothesis is extremely visionary, and I do not present it seriously, for it is almost impossible to conceive of any way in which the isolated beams of light could be formed, unless, perhaps, by vortex funnels more highly luminous than the surrounding surface of the sun. Such fanciful speculations are hardly worth indulging in, though they have interested me for the moment in connection with the matter of fossible curvature of light rays in the sun's atmosphere, alluded to in a recent paper by Julius in the Astrophysical Journal.

University of Wisconsin.

\section{The Alleged Decadence of German Chemistry.}

As a man of business, more or less interested in the course of chemical discovery in so far as it affects chemical products of market value, I have for so many years been accustomed to take note of the rapid strides made by Germany in the chemical industries, that the statement contained in the article by "W. J. P." in your issue of December 27 (p. 214) has struck me with amazement. The writer says that "all students of contemporary chemical literature will agree that in Germany the science of chemistry has been in rapid decadence during recent years." This statement seems to me so completely at variance with my own experience that $\mathbf{I}$ have consulted chemical friends as to its accuracy, and I cannot find any chemist who agrees with this verdict. The consensus of opinion is, in fact, all in the opposite direction. "W. J. P." himself admits, as a generally recognised principle, that supremacy in any particular industry goes hand in hand with supremacy in the related sciences. Every one of the discoveries recorded in his own paper has been made in Germany, and he himself points out that the new industry is "almost wholly of German origin." Of course, as an English merchant, I hold no brief for (ierman products, but having long ago recognised the importance of the connection between science and industry, which the author emphasises, and seeing what Germany has been doing of late years, I perhaps innocently attributed the progress of that country to their superior system of training in chemistry and related sciences, and to the readincss of their manufacturers to avail themselves of the results of scientific discovery. For the sake of British industry, I shall be only too glad to learn that I was mistaken ; but since no chemist of my acquaintance agrees with the writer, and since he himself puts forward a whole body of German discoveries in order to tell us that chemical science is undergoing "rapid decadence" in that country, I cannot but feel that there is such a glaring contradiction between the facts recorded and the conclusions arrived at by the writer that some further explanation as to his meaning is necessary.

S. N. C.

\section{Secondary Sexual Characters.}

Mr. Pocock (p. 157) has replied to my letter, but he has not replied to my reasoning. It is no reply to say that it may be doubted whether my hypothesis is an improvement on certain others, when no reasons are given for the doubt. It is no argument to say that a problem is insufficiently supported by evidence, and may be true or faise. A problem may be solved, but it cannot be either true or false, nor can it be supported by evidence. Mr. Pocock himself in his article attributed the colour of the male nilghaie and other antelopes to "male kafabolism," which he now says is nothing but an imposing substitute for the "vital force" of the pseudo-scientific realists. I quite agree with him, and only hope that in future he will not explain male peculiarities by attributing them to male katabolism.

It is very difficult to reason with a naturalist who uses the terms "struggle for existence" and " influence of external conditions " as equivalent to "selection." I quite understand that to the I)arwinian the only important action of external conditions is the selective action, the survival of the fittest. But the Darwinian does not appear to understand his opponents' conception of the modifying non-selective action of external conditions. Mr. Pocock does not distinguish between variations and modification. If any cause acts on all the males of a species and makes their colours dark or black, what effect can selection produce? If the dark colour is harmful, the species will become reduced or extinct. But selection cannot, as Mr. Pocock suggests, "check" a general modification due to a general cause without eliminating the species.

Thus the question which Mr. Pocock raised in his original article, and which he now "sets aside," the question of the initial cause of sexual modifications, is the essential question of the whole subject, and cannot be set aside in any rational discussion of the facts. Even supposing that the variations are different and not general, and that those which are beneficial are selected and preserved, selection offers no explanation of the fact that in so many cases the peculiarities in question are inherited only by the male sex. Mr. Pocock, in discussing the uses of coloration and markings, was obliged to refer to cases in which the males differed from the females both in colour and in horns. He has not yet realised the truth that no theories based on the conception of selection afford any explanation of unisexual inheritance.

Penzance, December 17, I900.

J. T. Cunvisgham.

\section{The Word Physiography.}

WITH reference to the question of the early use of the word Physiography to express the comprehensive study of Nature, to which you refer on p. 207 of your last issue, I should like to call attention to a fact which appears to have been almost forgotten.

The title-page of a "Dictionnaire des Termes usités dans les Sciences naturelles," published in Paris in 1834 , bears as a motto the words -

"Profectì physiographiam qui colit, ullo pacto metam perfectioris cognitionis feliciùs non attinget, quàm si aliquot dies terminis perdiscendis tribuerit."-Linne.

I have tried, but without success, to find this quotation in the works of Linneus; perhaps some of your readers may be able to supply the reference. The word Physiography was certainly current in Siveden about the middle of the eighteenth century, as in the obituary notice of Torbern Bergman, read at the Stockholm Academy of Sciences in 1786 (which I know only in the German translation), it is mentioned that he became a member "der Physiographischen (iesellschaft in Lund, I 776." "Minerva" for 1900-I90I, however, states that the Physiographical Society of Lund, which still exists, was founded in 177 8 for the study of the scientific and economic conditions of the province of Scania. There was at the same time a Cosmographic Society in Upsala, and the two names seem to have been used much in the same sense.

I think it possible that the word Physiography was introduced in Sweden by Linnæus as a substitute for Cosmography, the ancestor alike of the Physiography of South Kensington, and the Physical Geography of the older text-books.

No. 1627 , vOL. 63$]$ 